American Journal of Pharmaceutical Education 2020; 84 (5) Article 7230.

\title{
RESEARCH
}

\section{Using Virtual Patient Software to Improve Pharmacy Students' Knowledge of and Attitudes Toward Geriatric Patients}

\author{
Daniel Tenório da Silva, PhD, ${ }^{\mathrm{a}}$ André Mascarenhas Pereira, BPharm, ${ }^{\mathrm{b}}$ \\ Rafaella de Oliveira Santos Silva, MSc, ${ }^{b}$ Andrés Silva Menéndez, BSc, ${ }^{c}$ Cleverton dos Santos, BSc, ${ }^{c}$ \\ Isaias de Lima Florentino Júnior, BPharm, ${ }^{a}$ Sabrina Joany Felizardo Neves, PhD, ${ }^{\mathrm{d}}$ \\ Marcos Barbosa Dósea, MSc, ${ }^{\mathrm{c}}$ Divaldo Pereira Lyra Jr, $\mathrm{PhD}^{\mathrm{b}}$ \\ ${ }^{a}$ Federal University of Vale do São Francisco, College of Pharmacy, Petrolina, Pernambuco, Brazil \\ ${ }^{b}$ Federal University of Sergipe, Laboratory of Teaching and Research in Social Pharmacy, Faculty of Pharmacy, São \\ Cristóvão, Sergipe, Brazil \\ ${ }^{c}$ Federal University of Sergipe, Department of Computing, São Cristóvão, Sergipe, Brazil \\ ${ }^{\mathrm{d}}$ Federal University of Alagoas, Faculty of Nursing and Pharmacy, Macéio, Alagoas, Brazil
}

Submitted June 20, 2018; accepted September 24, 2019; published May 2020.

Objective. To evaluate the effect of using a virtual patient software program to improve pharmacy students' knowledge of and attitudes toward geriatric patients.

Methods. The Virtual Patient for Geriatric Education (VIPAGE) software program was used in two Bachelor of Pharmacy (BPharm) degree programs in Brazilian universities. The virtual consultations were divided into an initial evaluation, care plan, letter of referral to another professional, and evaluation of follow-up. Each weekly session lasted two hours. Students answered questionnaires before and after using the virtual patient software relating to the following: demographics, geriatric experiences, Geriatric Attitudes Scale, and the Facts on Aging Quiz.

Results. Of the 128 students who completed the baseline questionnaires, 109 students also completed the second questionnaire. The mean Geriatric Attitudes Scale score before the intervention was 3.7 $(\mathrm{SD}=0.8)$ and after was $3.9(\mathrm{SD}=0.7)$. Significant improvements in Geriatric Attitudes Scale scores after using the virtual patient software were seen in students who were male, whose grandparents were still alive, or whose parents were elderly, who had frequent contact with the elderly, who did not have frequent contact with the elderly, and who did not have professional contact with the elderly. The average score on geriatrics knowledge was $44.7(\mathrm{SD}=12.0)$ before completing the virtual patient consultations and $52.6(\mathrm{SD}=11.9)$ after. The mean score measuring students' lack of geriatrics knowledge was $27.3(\mathrm{SD}=15.8)$ before and $19.1(\mathrm{SD}=12.8)$ after using the software.

Conclusion. Completing virtual patient consultations using the VIPAGE software positively impacted pharmacy students' geriatrics knowledge and attitudes.

Keywords: geriatric education, virtual patient, pharmacy

\section{INTRODUCTION}

Computer simulation-based health care education is a growing field of teaching and research, with many related software applications entering mainstream medical education. This technology, often called virtual patient (VP) software, is a case-based computer program that combines textual information with multimedia elements such as audio, graphics, and animation. ${ }^{1}$ Over the last

Corresponding Author: Divaldo P. Lyra Jr., Laboratory of Teaching and Research in Social Pharmacy, Department of Pharmacy, Federal University of Sergipe, São Cristóvão, Sergipe, Brazil. Tel: +55 7999192 5577. Email: lepfs.ufs@gmail.com. decade, the use of VP technology, from computer-based virtual reality programs to full-size, lifelike simulators, has emerged as a new method of training health care providers in clinical and communication skills.

In pharmacy education, research involving the use of VP technology as a teaching tool is still scarce. ${ }^{2}$ Several studies have evaluated the use of VP in pharmacy practice competency development, noting that the use of this teaching strategy allows optimization of clinical skills, pharmacotherapeutic evaluation skills, and communication skills. ${ }^{2-6}$

In the United States, the use of simulation in pharmacy education, like that made possible by VP technology, is recognized and encouraged by the Accreditation 


\section{American Journal of Pharmaceutical Education 2020; 84 (5) Article 7230.}

Council for Pharmacy Education and has been effective in the development of clinical competencies and knowledge retention by pharmacy graduate students. ${ }^{7}$ Virtual patient technology has the potential to overcome many of the challenges presented by the current educational structure, including reduced access to real patients, lack of standardization in consultations, large number of students in classes, and the inherent risks of allowing students to provide care to patients with complex illnesses, such as elderly patients. ${ }^{1}$

There has been some effort to assess which teaching methods may be more effective for the inclusion of geriatric themes in order to optimize future pharmacists' competencies in caring for the elderly because they are the largest consumers of medications. ${ }^{8}$ In this context, the increasing emphasis on competency development-based education affirms the exploration of the role of VP technology in geriatric education. ${ }^{9}$ However, although some geriatrics programs have started using VP software as a teaching tool, its use has not been widespread, especially in pharmacy colleges. ${ }^{1,10}$ Because of the demographic and epidemiological differences of the elderly population, health care professionals' training must adequately cover the specific needs of this group.

In light of this, the Virtual Patient for Geriatric Education (VIPAGE) software was developed by the Laboratory of Teaching and Research in Social Pharmacy, Pharmacy Department, in partnership with the Computer Science Department, at the Federal University of Sergipe, Brazil. All patient profiles used in the software were based on actual elderly patients to allow students to experience the specific aspects and difficulties of providing pharmaceutical care to this patient group. The patients were people cared for by the pharmacists who participated in the development of the tool. The software was designed to address all biopsychosocial aspects of the elderly (physiological, pathological, income, social rights, and psychological health) in order to broaden students' geriatrics competencies.

In the design phase, all system requirements, including definition of the methodology used for the pharmaceutical care documentation process, number of queries, student response fields, and feedback configuration, were collected through weekly meetings conducted by computing and pharmacy researchers. Two prototype models of the system were presented by computer and pharmacy researchers (full-time faculty members and clinical researchers) to determine face and content validity. After the creation of the software, a set of techniques were developed and tests performed to verify the interaction and integration of the components, to evaluate if all the proposed requirements were implemented, and to guarantee correction of defects before implementation.

After the conclusion of the software engineering process, the validation of the internal (efficiency, maintainability, and portability) and external (functionality, reliability, and usability) quality of the VIPAGE software was performed by computer specialists in software development. Members of the pharmacy team validated the functionality of the system through pilot tests and the inclusion of responses to clinical cases by software users, allowing for the correction of programming and interpretation of content errors.

The aim of this study was to evaluate the effect of VIPAGE software in pharmacy students' geriatrics knowledge and attitudes.

\section{METHODS}

A longitudinal and prospective study was conducted to evaluate students' competencies in relation to geriatrics before and after using the VIPAGE software. The methodology was divided into three main phases: initial assessment of students' competencies (pretest), application of the VIPAGE software, and final evaluation of students' competencies (posttest).

The study was approved by the Research Ethics Committee of Federal University of Sergipe, with the virtual patient software implemented in two Bachelor of Pharmacy programs located in northeastern Brazil (Federal University of Sergipe and Federal University of Alagoas). The software was used in the first- and second-semester (September 2014 and December 2015) of the required Pharmaceutical Care course (30 hours of contact).

Initially, a presentation of the software was delivered to students by the pharmacy course instructors (who did not participate in the evaluation of the software) in the classroom, with computer projection on a big screen and tutorials on how to use the software were made available to the students. Weekly VIPAGE use sessions lasted two hours each and were held over a four-week period, amounting to eight hours of instruction. In these sessions students used an individual computer. The four virtual patient consultations in VIPAGE included:

Initial evaluation: students registered themselves on the system, performed the login process, and then selected one of the virtual clinical cases. Shortly after, information on the selected virtual patient (age, gender, medical conditions, pharmacotherapeutic profile, subjective experiences with medications, allergies, laboratory and physical test results, etc) was made available in the system so that the students could assess the virtual patient, 


\section{American Journal of Pharmaceutical Education 2020; 84 (5) Article 7230.}

corresponding to the first visit of a pharmaceutical care program;

Care plan: new information related to the drug therapy problems of the virtual patient was posted on the system for the creation of care plans by the students. A care plan included the following: identification, prevention, and/or resolution alternatives of the drug therapy problems; pharmaceutical interventions performed, and identification of the stake holders (patient, physician, and other healthcare professionals) required to be involved in the process to solve the drug therapy problems;

Letter of referral to another health professional: fields were arranged in the system for the preparation of a technical report to be sent to a doctor or to other healthcare professionals. This report contained the following: virtual patient information; motives for referral appointment; proposed resolution alternatives for the drug therapy problems; name, contact, and registration number of the fictitious pharmacist; and references;

Evaluation of follow-up: new information on the clinical course of virtual patients was made available in the system for students to carry out the follow-up evaluation: analyzing the situation of the drug therapy problems, setting the date of the next appointment with the virtual patient, and drafting the personal journal of medicinal products.

Each class had up to 30 students, and the students were divided into groups of four for each VIPAGE consultation. Students interacted with the virtual patient on desktop computers, typing their responses in the fields of the medical record. Each module had 12 to 35 fields to be answered. Each group had three chances to resolve the questions posed by virtual patients. Instructors then made the necessary corrections for the complete resolution of the case, and then graded the students' performance in the simulation using the grading tool included in the software. In the final 22 hours of the course, content was presented in lecture format but did not include information on geriatric subjects.

The evaluation of students' geriatric competencies (ie, knowledge and attitudes) was supervised by investigators and performed at the beginning of the course and four weeks later, immediately after the application of the software, in order to allow before-after evaluation outside of class time. The students were informed that the evaluation was anonymous to avoid any possible bias in its completion. The use of VIPAGE was included in the formal content of the subjects and the software was used to assess students' grades, but participation in the research was voluntary

A content-validated, semi-structured questionnaire based on the literature ${ }^{8}$ was developed by the researchers in consultation with a panel of experts in geriatrics. The questionnaire was intended to evaluate students' previous experiences living with elderly persons and their perspectives regarding the elderly. The students' intentions and perspectives on working in elderly care were also evaluated (The opportunities of geriatric careers in Brazil are similar to those of the US).

The students' attitudes toward the elderly were evaluated using the widely validated Geriatric Attitudes Scale (GAS). ${ }^{11}$ The GAS is a 14 -item questionnaire with a mix of positively and negatively worded questions, with responses graded on a five-point Likert scale ranging from $1=$ strongly disagree to $5=$ strongly agree, with $3=a$ neutral response. It consists of five positively worded and nine negatively worded items and has the advantage of being easy to administer and score. Scores of negatively worded GAS statements are inverted (eg, 5 to 1,4 to 2 ) before being added to scores for positively worded statements to produce an average Likert score. Attitudes were also evaluated according to the following subdomains: medical care provided to the elderly, social value of the elderly, compassion for the elderly, and distribution of social resources for the elderly.

Competency, ie, students' knowledge on geriatric subjects, was evaluated by administering the Facts on Aging Quiz (FAQ), a 25-question true-false test that assesses general knowledge of aging issues. The quiz covers physiological, psychological, and sociological concepts, as well as common misconceptions about aging. ${ }^{12,13}$ Higher scores on the FAQ have been found to correlate with higher educational levels and greater exposure to aging issues. The FAQ also evaluated students' biases in relation to the elderly, based on the assumption that certain misconceptions about the elderly indicate a positive or negative bias. ${ }^{12}$

A quantitative evaluation of VIPAGE was performed by students using a combination of two instruments adapted from Hussein and Kawahara ${ }^{14}$ and Zary and colleagues. ${ }^{15}$ The instruments consisted of $19 \mathrm{ob}-$ jective questions, of which 10 were adapted from Hussein and Kawahara, seven were adapted from Zary and colleagues, and two were added to assess the performance of instructors. ${ }^{14,15}$ These instruments were used to assess students' acceptance of, use of, learning of, and satisfaction with VIPAGE. The responses were graded using a Likert scale ranging from $1=$ strongly disagree to $5=$ strongly agree.

All the instruments used were reviewed by the researcher, and all results were computed in Epi Info, version 3.3 (US Centers for Disease Control and Prevention, Atlanta, GA). To compare the students' competencies before and after the educational interventions, the $t$ test 


\section{American Journal of Pharmaceutical Education 2020; 84 (5) Article 7230.}

was used for related samples. The differences between competency scores and sociodemographic characteristics of the participants was evaluated using the independent $t$ test. An analysis of variance (ANOVA) was conducted to compare the differences between the subdomains of the GAS scale. Two-tailed post hoc tests (Bonferroni and Tukey) were conducted on significant ANOVA results. A statistically significant $95 \%$ confidence interval $(p<.05)$ was found.

\section{RESULTS}

The sociodemographic characteristics, personal and academic experiences with the elderly of the 128 students at baseline are presented in Table 1. Regarding professional performance, $105(82.1 \%)$ students considered working in some area of pharmacy that included contact with the elderly, and $106(82.8 \%)$ agreed (or partially agreed) that the professional area they planned to work in might be influenced by the age category of the population (Table 1).

One hundred twenty-eight students completed the GAS and FAQ at baseline, and 109 (85.1\%) students completed the second assessment, of whom 18 decided not to participate in the study and one missed the class. After using the VIPAGE software in the subject, the student's attitudes toward the elderly demonstrated significant change. The mean (SD) GAS score before using the software was $3.7(0.8)$ and the mean score afterward was $3.9(0.7 ; p<.01$; Table 2$)$. The students demonstrated unfavorable attitudes in their response to only two of the 14 items.

In relation to the four GAS subdomains, ANOVAs showed a significant difference $(p<.001)$ in intergroup attitudes toward the elderly among all four subdomains. However, after comparing before and after intragroup results, a significant difference in only two of the subdomains was seen (Table 3).

No significant difference was seen in the mean scores of attitudes toward the elderly between genders in the pretest or posttest evaluation. However, a significant difference was observed in the mean scores of male students before and after the use of VIPAGE $(p=.008)$ (Table 4). In relation to personal experience with the elderly, a significant difference was detected in GAS scores, before and after the use of VIPAGE, of students whose grandparents were still alive or whose parents were elderly $(p=.003)$, students who had frequent contact with the elderly $(p=.03)$, and students who did not have frequent contact with the elderly $(p=.005)$.

No significant difference was seen after use of VIPAGE in the GAS scores of students who had previous professional contact with the elderly $(p=.18)$. However, students who did not have previous professional contact with the elderly had significantly higher GAS scores after using VIPAGE $(p=.006)$. In addition, among students who previously had not considered working in areas that required contact with the elderly, there was a significant increase in scores, which reflected students' improved attitudes toward the elderly after using VIPAGE $(p=.002)$.

When the pretest and posttest scores on the FAQ were compared, a significant increase was seen in students' knowledge about geriatric subjects (Table 2). The students' average (SD) knowledge score for geriatric subjects was 44.7 (12.0) before they used VIPAGE and 52.6 (11.9) after $(p=.003)$. The mean "unknown" (percentage of questions answered "I do not know") score on the FAQ was 27.3 (15.8) before and 19.1 (12.8) after using VIPAGE $(p=.02)$. A significant decrease was seen in students' negative bias toward the elderly $(p=.007)$, but a significant increase was not found in positive bias toward the elderly in a comparison of before-after scores $(p=.24)$.

In this study, significant differences were found in the percentage of correct answers $(p=.005)$ and the rate of assumed ignorance $(p=.03)$ between genders, with men having higher "knowledge" scores and lower "assumed ignorance" scores (Table 4). In addition, there was a significant difference in the percentage of correct responses on FAQs and in "do not know" responses before and after using VIPAGE in students whose grandparents were still alive or who had elderly parents $(p=.01$ and $p=.02$, respectively), and of students who do not have frequent contact with the elderly (correct responses on FAQs $p=.004$; "do not know" $p=.05$ ). Students who did not have frequent contact with the elderly had a significantly lower correct response rate on the pretest compared with those who had frequent contact with the elderly $(p=.006)$. After the use of VIPAGE, an increase in the correct response rate was seen and there was no longer a significant difference in responses between these students $(p=.30)$.

The rate of correct FAQ answers in the pretest of students who did not have previous professional contact with the elderly was significantly lower compared to students who had previous professional contact with the elderly $(p=.03)$, but a significant difference was not observed in the posttest rate $(p=.25)$. The correct answer rate, Mean (SD) for the students who considered working in areas that allowed contact with the elderly was 46.0 (13.0) before and 52.1 (11.3) after using the VIPAGE software $(p=.03)$. Similarly, there was also a significant difference in the rate of correct answers before and after completing the VIPAGE consultations for students who did not consider working with the elderly in the future $(p=.01)$. 


\section{American Journal of Pharmaceutical Education 2020; 84 (5) Article 7230.}

Table 1. Baseline Sociodemographic Characteristics, Personal and Academic Experience with Geriatrics of Bachelor of Pharmacy Students

Participants $(\mathrm{n}=128) \mathrm{n}(\%)$

\begin{tabular}{|c|c|}
\hline \multicolumn{2}{|l|}{$\overline{\text { Gender }}$} \\
\hline Female & $91(71)$ \\
\hline Male & $37(29)$ \\
\hline \multicolumn{2}{|l|}{ Age (Mean, SD) } \\
\hline Mean (SD) & $24(3.0)$ \\
\hline Minimum - Maximum & $20-37$ \\
\hline $20-23$ & $52(40.6)$ \\
\hline $24-27$ & $68(53.1)$ \\
\hline$\geq 28$ & $8(6.3)$ \\
\hline \multicolumn{2}{|l|}{ Year course } \\
\hline $2 \mathrm{Y}$ & $6(4.6)$ \\
\hline $3 \mathrm{Y}$ & $7(5.4)$ \\
\hline $4 \mathrm{Y}$ & $48(37.5)$ \\
\hline $5 \mathrm{Y}$ & $67(52.3)$ \\
\hline \multicolumn{2}{|l|}{ Grandparents are alive } \\
\hline Yes & $108(84.3)$ \\
\hline No & $20(15.7)$ \\
\hline \multicolumn{2}{|l|}{ Parents are elderly ${ }^{\mathrm{a}}$} \\
\hline Yes & $16(12.5)$ \\
\hline No & $112(87.5)$ \\
\hline \multicolumn{2}{|c|}{ Frequent contact with older people ${ }^{b}$} \\
\hline Yes & $78(60.9)$ \\
\hline No & $50(39.1)$ \\
\hline \multicolumn{2}{|l|}{ Frequency of contact $(n=78)$} \\
\hline Less than once per week & $8(10.2)$ \\
\hline Once a week & $19(24.4)$ \\
\hline 2 to 3 times per week & $38(48.8)$ \\
\hline 4 to 5 times per week & $5(6.4)$ \\
\hline Every day & $8(10.2)$ \\
\hline \multicolumn{2}{|c|}{ Previous professional contact with elderly patients? } \\
\hline Yes & $60(46.9)$ \\
\hline No & $68(53.1)$ \\
\hline \multicolumn{2}{|c|}{ Did you have contact with geriatrics related topics in the pharmacy disciplines? } \\
\hline Yes & $14(10.9)$ \\
\hline No & $114(89.1)$ \\
\hline \multicolumn{2}{|c|}{$\begin{array}{l}\text { After graduation, have you ever considered working in any area that allows } \\
\text { contact with the elderly? }\end{array}$} \\
\hline Yes & $105(82.1)$ \\
\hline No & $23(17.9)$ \\
\hline \multicolumn{2}{|c|}{$\begin{array}{l}\text { You think that your area of professional performance can be modified due to the } \\
\text { process of population aging? }\end{array}$} \\
\hline Disagree & $6(4.6)$ \\
\hline Somewhat Disagree & $4(3.2)$ \\
\hline Neutral & $12(9.4)$ \\
\hline Somewhat Agree & $39(30.4)$ \\
\hline Agree & $67(52.4)$ \\
\hline
\end{tabular}

$\mathrm{SD}=$ Standard Deviation. ${ }^{\mathrm{a}} \geq 60 \mathrm{y}$ (classification of the World Health Organization for developing countries), ${ }^{\mathrm{b}}$ personal contact according to the frequency of distribution 
American Journal of Pharmaceutical Education 2020; 84 (5) Article 7230.

Table 2. Comparison of Geriatric Attitudes Scale (GAS) and Facts on Aging Quiz (FAQ) Scores of Pharmacy Students Before and After Using Geriatric Education Software

\begin{tabular}{|c|c|c|c|}
\hline & Pretest Mean (SD) & Pos-test Mean (SD) & $p$ Value \\
\hline \multicolumn{4}{|l|}{ GAS } \\
\hline \multicolumn{4}{|l|}{ Positively worded items } \\
\hline Most old people are pleasant to be with. $(+)^{\mathrm{a}}$ & $3.9(1.0)$ & $4.2(0.9)$ & .01 \\
\hline It is society's responsibility to care for its elderly patients. $(+)$ & $4.7(0.8)$ & $4.6(1.0)$ & .67 \\
\hline $\begin{array}{l}\text { Elderly patients will appreciate my pharmaceutical care more } \\
\text { than younger patients. }(+)\end{array}$ & $3.9(1.1)$ & $4.0(1.0)$ & .33 \\
\hline $\begin{array}{l}\text { I will tend to pay more attention and have more sympathy } \\
\text { towards my elderly patients than my younger patients. }(+)\end{array}$ & $3.6(1.2)$ & $3.8(1.2)$ & .45 \\
\hline $\begin{array}{l}\text { It is interesting listening to old people's accounts of their past } \\
\text { experiences. }(+)\end{array}$ & $4.6(0.7)$ & $4.7(0.6)$ & .29 \\
\hline \multicolumn{4}{|l|}{ Negatively worded items ${ }^{b}$} \\
\hline $\begin{array}{l}\text { The federal government should reallocate money from elderly } \\
\text { health programs to research on AIDS or pediatric diseases. }(+)\end{array}$ & $4.1(1.4)$ & $4.2(1.3)$ & .55 \\
\hline $\begin{array}{l}\text { If I have the choice, I would rather see younger patients than } \\
\text { elderly ones. }(+)\end{array}$ & $3.4(1.2)$ & $3.5(1.1)$ & .55 \\
\hline $\begin{array}{l}\text { Medical care for old people uses up too much human and } \\
\text { material resources. (-) }\end{array}$ & $1.8(0.9)$ & $2.1(1.1)$ & .01 \\
\hline $\begin{array}{l}\text { As people grow older, they become less organized and more } \\
\text { confused. }(+)\end{array}$ & $2.8(1.2)$ & $3.1(1.4)$ & .07 \\
\hline $\begin{array}{l}\text { Taking a medical history from elderly patients is frequently an } \\
\text { ordeal. }(+)\end{array}$ & $3.2(1.2)$ & $3.7(1.2)$ & .001 \\
\hline Old people in general do not contribute much to society. $(+)$ & $4.6(0.9)$ & $4.6(0.9)$ & .65 \\
\hline Treatment of chronically ill old patients is hopeless. $(+)$ & $4.3(1.0)$ & $4.4(1.0)$ & .97 \\
\hline $\begin{array}{l}\text { Old persons don't contribute their fair share in paying for their } \\
\text { healthcare. }(+)\end{array}$ & $4.3(0.9)$ & $4.4(0.9)$ & .21 \\
\hline In general, old people act too slow for modern society. $(+)$ & $3.8(1.10$ & $3.7(1.2)$ & .40 \\
\hline Mean GAS Score & $3.7(0.8)$ & $3.9(0.7)$ & .01 \\
\hline \multicolumn{4}{|l|}{ FAQ } \\
\hline FAQ\% correct responses & $44.7(12.0)$ & $52.6(11.9)$ & .003 \\
\hline FAQ\% don't know responses & $27.3(15.8)$ & $19.1(12.8)$ & .02 \\
\hline FAQ\% positive bias ${ }^{\mathrm{c}}$ & $4.4(9.2)$ & $6.8(11.1)$ & .24 \\
\hline FAQ $\%$ negative bias ${ }^{\mathrm{d}}$ & $32.6(15.4)$ & $25.6(13.3)$ & .007 \\
\hline FAQ\% net bias ${ }^{\mathrm{e}}$ & $-28.2(19.2)$ & $-18.8(16.8)$ & .01 \\
\hline
\end{tabular}

a Plus sign (+) after an item indicates that students had a positive attitude about that item, while a minus sign (-) indicates students had a negative attitude about that item even after the VIPAGE use

${ }^{\mathrm{b}}$ Scores of negatively worded GAS statements are reversed before being added to scores for the positively worded statements to produce an average Likert score

${ }^{\mathrm{c}}$ Positive bias: \% FAQ positive items incorrect responses

${ }^{\mathrm{d}}$ Negative bias: \% FAQ negative items incorrect responses

e Net bias: \% FAQ positive bias score minus negative bias score

$\mathrm{SD}=$ Standard Deviation

The software evaluation showed the total mean score generated by the instrument was $4.2(0.5)$. Among the students, $95.8 \%$ agreed or fully agreed with the statement, "The teaching approach used with VIPAGE was significantly different from other approaches I have encountered in the past" (Table 5). In addition, $98 \%$ of the students agreed or fully agreed with the statement, "Considering the fact that patient outcomes were affected according to my care plan, the approach used with VIPAGE made me focus and pay more attention to the details, and therefore improved my learning process." However, 29.1\% of the 128 students disagreed or fully disagreed with the item, "The technology used in VIPAGE did not cause me to spend much time filling out the patient's medical record." Overall $98 \%$ of students (Average $=4.4, \mathrm{SD}=0.5$ ) assessed the VIPAGE software as good or very good (Table 5).

\section{DISCUSSION}

In addition to significantly improving students' knowledge, the use of VIPAGE significantly increased 


\section{American Journal of Pharmaceutical Education 2020; 84 (5) Article 7230.}

Table 3. Comparison of Geriatric Attitudes Scale Subdomains Scores of Bachelor of Pharmacy Students Before and After Using a Virtual Software Program

\begin{tabular}{|c|c|c|c|}
\hline Variable & $\begin{array}{c}\text { Pretest } \\
\text { Mean (SD) }\end{array}$ & $\begin{array}{c}\text { Pos-test } \\
\text { Mean (SD) }\end{array}$ & $\begin{array}{c}p \text { Value } \\
\text { (intragroup) }\end{array}$ \\
\hline $\begin{array}{l}\text { Social Value } \\
\text { In general, old people act too slow for modern society. } \\
\text { Old persons don't contribute their fair share in paying for their healthcare. }\end{array}$ & $4.0(1.0)$ & $4.1(1.1)$ & .84 \\
\hline $\begin{array}{l}\text { Medical Care } \\
\text { Taking a medical history from elderly patients is frequently an ordeal. } \\
\text { As people grow older, they become less organized and more confused. } \\
\text { If I have the choice, I would rather see younger patients than elderly ones. } \\
\text { Treatment of chronically ill old patients is hopeless. }\end{array}$ & $3.3(1.3)$ & $3.6(1.7)$ & .002 \\
\hline $\begin{array}{l}\text { Compassion } \\
\text { Elderly patients will appreciate my pharmaceutical care more than younger } \\
\text { patients. } \\
\text { I will tend to pay more attention and have more sympathy towards my } \\
\text { elderly patients than my younger patients. } \\
\text { Most old people are pleasant to be with. } \\
\text { It is interesting listening to old people's accounts of their past experiences. }\end{array}$ & $3.9(1.0)$ & $4.1(1.0)$ & .007 \\
\hline $\begin{array}{l}\text { Resources Distribution } \\
\text { The federal government should reallocate money from elderly health } \\
\text { programs to research on AIDS or pediatric diseases. } \\
\text { It is society's responsibility to care for its elderly patients. } \\
\text { Medical care for old people uses up too much human and material } \\
\text { resources. } \\
\text { Old people in general do not contribute much to society. }\end{array}$ & $3.7(1.5)$ & $3.8(1.4)$ & .08 \\
\hline$p$ value (intergroup) & $<.001$ & $<.001$ & \\
\hline
\end{tabular}

$\mathrm{SD}=$ Standard Deviation. Responses are graded on a 5-point Likert scale ranging from strongly disagree (1) to strongly agree (5), a rating of 3 indicates a neutral response. In the score, 5 represents that attitudes are more positive, 1 represents more negative attitudes

students' average GAS scores, even on items that indicated negative attitudes. The literature points to several strategies that have been effective in improving the skills of pharmacy undergraduates in relation to care of the elderly; however, this is the first one to use a VP tool for this purpose. ${ }^{16,17}$ The changes in students' knowledge and attitudes may have been associated with the fact that VIPAGE software was developed to provide students with a realistic experience of interacting with an elderly patient and is not merely a strategy for conveying information. Teaching interventions that are solely intended to increase knowledge are generally ineffective in changing students' attitudes. In contrast, interventions that include empathy-building teaching strategies are associated with a greater likelihood of positive change in participants' attitudes. ${ }^{18}$

Regarding the four subdomains of the GAS, although the pharmacy students were pursuing a health care degree, they scored lower on questions in the subdomain 'medical care for the elderly' at baseline. Students' worsening attitudes toward providing medical care for the elderly may reinforce the argument that students having personal or professional experience with geriatric patients who were sick is detrimental to the students' attitudes toward them. The VIPAGE software was able to significantly modify students' attitudes in this subdomain, confirming its usefulness for the teaching of geriatrics in a medical course. There was also a significant change in students' scores in the subdomain "compassion for the elderly," validating the software's potential to develop perceptions that go beyond the biological aspects of aging. Lee and colleagues suggested that the domains "medical care for the elderly" and "compassion for the elderly" were the two domains most strongly associated with choosing a career in geriatrics. ${ }^{19}$

The results of this study showed that students' gender had no relation to their attitudes to the elderly. Similarly, previous studies have shown that demographic factors were not related to students' attitudes toward the elderly. ${ }^{20}$ However, in relation to gender, our study found there was a significant difference in the attitudes of male students compared to female students in mean GAS scores and the "knowledge" and the "don't know" rates on the FAQ before and after using the VIPAGE software. As gender does not appear to be a consistent predictor for better study competence, this may be associated with the 
American Journal of Pharmaceutical Education 2020; 84 (5) Article 7230.

Table 4. Comparison of Geriatric Attitudes Scale (GAS) and Facts on Aging Quiz (FAQ) Scores of Pharmacy Students Before and After VIPAGE Use by Socio-Demographic Characteristics, Personal and Professional Experience with Elderly

\begin{tabular}{|c|c|c|c|c|c|c|c|c|c|}
\hline \multirow[b]{2}{*}{ Variable } & \multicolumn{3}{|c|}{ Geriatric Attitudes Scale } & \multicolumn{3}{|c|}{ FAQ\% Correct Responses } & \multicolumn{3}{|c|}{ FAQ\% Don't Know Responses } \\
\hline & $\begin{array}{l}\text { Pretest } \\
\text { Mean } \\
\text { (SD) }\end{array}$ & $\begin{array}{l}\text { Post-test } \\
\text { Mean } \\
\text { (SD) }\end{array}$ & $\begin{array}{c}p \\
\text { Value }\end{array}$ & $\begin{array}{l}\text { Pretest } \\
\text { Mean } \\
\text { (SD) }\end{array}$ & $\begin{array}{l}\text { Post-test } \\
\text { Mean } \\
\text { (SD) }\end{array}$ & $\begin{array}{c}p \\
\text { Value }\end{array}$ & $\begin{array}{l}\text { Pretest } \\
\text { Mean } \\
\text { (SD) }\end{array}$ & $\begin{array}{c}\text { Post-test } \\
\text { Mean } \\
\text { (SD) }\end{array}$ & $\begin{array}{c}p \\
\text { value }\end{array}$ \\
\hline \multicolumn{10}{|l|}{ Gender } \\
\hline Male & $3.7(0.7)$ & $3.9(0.7)$ & .008 & $47.0(14.1)$ & $59.2(9.8)$ & .004 & $28.4(15.0)$ & $13.5(9.2)$ & .003 \\
\hline Female & $3.8(0.8)$ & $3.8(0.6)$ & .24 & $44.1(12.0)$ & $49.4(11.6)$ & .04 & $25.7(16.5)$ & $21.7(13.5)$ & .17 \\
\hline$p$ value & .84 & .80 & & .43 & .005 & & .56 & .03 & \\
\hline \multicolumn{10}{|c|}{$\begin{array}{l}\text { Grandparents are alive or } \\
\text { parents are elderly }\end{array}$} \\
\hline Yes & $3.7(0.8)$ & $3.9(0.7)$ & .003 & $45.4(13.3)$ & $53.2(12.6)$ & .01 & $25.5(15.9)$ & $17.5(12.0)$ & .02 \\
\hline No & $3.8(0.8)$ & $3.8(0.6)$ & .74 & $42.5(7.8)$ & $48.5(7.4)$ & .10 & $32.5(13.5)$ & $27.4(15.5)$ & .13 \\
\hline$p$ value & .83 & .59 & & .55 & .34 & & .25 & .06 & \\
\hline \multicolumn{10}{|c|}{$\begin{array}{l}\text { Frequent contact with older } \\
\text { people }\end{array}$} \\
\hline Yes & $3.8(0.8)$ & $3.9(0.6)$ & .03 & $48.8(12.8)$ & $53.9(11.9)$ & .10 & $23.5(14.2)$ & $18.3(11.7)$ & .12 \\
\hline No & $3.6(0.8)$ & $3.8(0.7)$ & .005 & $37.8(9.5)$ & $50.3(11.7)$ & .004 & $30.9(13.5)$ & $20.4(15.5)$ & 0.05 \\
\hline$p$ value & .54 & .09 & & .006 & .30 & & .08 & .57 & \\
\hline \multicolumn{10}{|c|}{$\begin{array}{l}\text { Previous professional contact } \\
\text { with elderly patients? }\end{array}$} \\
\hline Yes & $3.8(0.8)$ & $3.9(0.7)$ & .18 & 48.9 (13.7) & $54.7(12.7)$ & .07 & $23.6(14.7)$ & $18.3(12.3)$ & .10 \\
\hline No & $3.7(0.8)$ & $3.9(0.7)$ & .006 & 41.8 (11.6) & $50.8(11.2)$ & .006 & $28.9(16.9)$ & $19.7(13.3)$ & 0.05 \\
\hline$p$ value & .61 & .82 & & .03 & .25 & & .22 & .71 & \\
\hline \multicolumn{10}{|c|}{$\begin{array}{l}\text { After graduation, have you } \\
\text { ever considered working } \\
\text { in any area that allows } \\
\text { contact with the elderly? }\end{array}$} \\
\hline Yes & $3.7(0.8)$ & $3.9(0.7)$ & .02 & $46.0(13.0)$ & $52.1(11.3)$ & .03 & $24.0(14.8)$ & $20.1(12.9)$ & .11 \\
\hline No & $3.6(0.8)$ & $3.8(0.8)$ & .002 & $40.4(10.9)$ & $54.2(14.8)$ & .01 & $38.0(17.7)$ & $14.2(11.6)$ & .009 \\
\hline$p$ value & .43 & .50 & & .21 & .64 & & .01 & .20 & \\
\hline
\end{tabular}

$\mathrm{SD}=$ Standard Deviation

VIPAGE gaming feature and the fact that men generally spend more time playing digital games than women. ${ }^{19}$ As size and composition of the sample may influence the result, larger studies with virtual teaching tools need to be performed to confirm or refute this hypothesis.

There was not a significant difference in mean GAS scores or knowledge rate on geriatric subjects between students with elderly relatives and those without elderly relatives. Similarly, a study by Sahin and colleagues determined that having an elderly relative is not a predictor of positive attitudes toward the elderly. ${ }^{20}$ However, the significant difference in the mean GAS score of students who had elderly relatives before and after using the VIPAGE software can be explained by the fact that empathy for the elderly may be influenced by family and home experiences. This was corroborated by the study result indicating a significant change in the attitudes of those who had frequent contact with the elderly, further validating previous studies which determined that the attitudes of those who live with the elderly are more positive toward elderly people in general. ${ }^{23,24}$ By living with an elderly person, students can see the application of the content of the VIPAGE software in their daily routine, and develop empathy for patients and their needs in a desire to learn more so they can provide the best care for their relatives.

Significant changes in the average GAS scores of attitudes and "knowledge" and "I do not know" rates on FAQ before and after using the VIPAGE software of students who did not have frequent contact with the elderly and students who did not have previous professional contact with the elderly demonstrate the effectiveness of VIPAGE. The students' competences (knowledge and attitudes) were positively modified, demonstrating the effectiveness of the virtual patient, even in students who had no personal or professional contact with the elderly. Students' comfort levels with the elderly are likely to increase as their interaction with geriatric patients 
American Journal of Pharmaceutical Education 2020; 84 (5) Article 7230.

Table 5. Evaluation of VIPAGE Software by Pharmacy Students

\begin{tabular}{|c|c|}
\hline & Mean (SD) \\
\hline $\begin{array}{l}\text { 1. The teaching approach used in the VIPAGE was significantly different from other approaches that I have } \\
\text { encountered in the past. }\end{array}$ & $4.7(0.6)$ \\
\hline $\begin{array}{l}\text { 2. The Care Plan template that was used helped me organize my thoughts as my group worked on complicated } \\
\text { patient cases. }\end{array}$ & $4.2(0.9)$ \\
\hline $\begin{array}{l}\text { 3. The patient case scenarios helped me understand that patients do not always respond like the textbook say they } \\
\text { should. }\end{array}$ & $4.1(0.9)$ \\
\hline 4. The VIPAGE helped me gain more confidence in my ability to apply the information therapies. & $4.0(1.1)$ \\
\hline 5. The technology used in the VIPAGE was operational (functioned properly) $75 \%$ of the time or more. & $4.1(1.0)$ \\
\hline 6. The approach used in the VIPAGE with regard to data collection not consumed too much time. & $3.3(1.3)$ \\
\hline $\begin{array}{l}\text { 7. The approach used in this system with regard to data collection made this VIPAGE more realistic than other } \\
\text { courses that include written case presentations/discussions. }\end{array}$ & $4.3(0.7)$ \\
\hline $\begin{array}{l}\text { 8. The approach used in the VIPAGE with regard to the fact that patient outcomes were affected by my work (ie, } \\
\text { assessment, placing medical and laboratory orders) made me concentrate and pay more attention to details, and } \\
\text { thus enhanced my learning process. }\end{array}$ & $4.5(0.5)$ \\
\hline 9. The VIPAGE challenged me. & $4.1(0.9)$ \\
\hline 10. The VIPAGE enhanced my understanding of topics or diseases that were covered in other classes. & $4.2(0.8)$ \\
\hline 11. I had no problems learning to use the VIPAGE. & $4.2(0.9)$ \\
\hline 12. I found the cases in VIPAGE engaging. & $4.2(0.9)$ \\
\hline 13. I found the cases in VIPAGE realistic. & $4.2(1.0)$ \\
\hline 14. I found the cases in VIPAGE instructive. & $4.2(0.9)$ \\
\hline 15. I found VIPAGE fun to use. & $4.1(0.9)$ \\
\hline 16. I think that I learn using VIPAGE. & $4.5(0.6)$ \\
\hline 17.What is your overall evaluation of the VIPAGE? & $4.4(0.5)$ \\
\hline 18.How do you evaluate the tutorship process performed within the VIPAGE? & $4.5(0.5)$ \\
\hline 19.How do you evaluate instructors of the VIPAGE? & $4.6(0.5)$ \\
\hline
\end{tabular}

increases during the course. ${ }^{25}$ Thus, using the VIPAGE software may effectively emulate interacting with actual patients, or at least prepare students for real patient contact in the future. The software replicates real clinical case scenarios, allowing students to take on the role of health care provider in a safe environment and to develop clinical skills such as assessing an elderly patient, interviewing an elderly patient, and communicating information.

Significant differences in attitudes among students who considered working in areas that allow contact with the elderly and those who did not may highlight two points concerning the use of VIPAGE software. First, the software can optimize the skills of students who want to work with the elderly so that they feel more professionally prepared and improve the quality of work of future pharmacists in specific geriatric areas. Second, among students previously not interested in working with the elderly, the software has the potential to inspire their interest in working in this emerging labor market, given the different pharmaceutical services needed by this population.

Regarding students' attitudes toward the elderly, we saw a significant reduction in negative biases and an increase in positive attitudes following completion of the VIPAGE software. Several studies have shown that when students are exposed to integrated teaching strategies, there is a positive effect on attitudes demonstrated toward the elderly. ${ }^{25,26}$ A reduction in the negative bias assessed through the FAQ was seen, but there was no significant increase in the positive bias of students in the pretest and posttest. This may indicate that the effect of VIPAGE was to reduce overall bias. The reduction of bias in relation to the elderly is a very important strategy to be included in any geriatric teaching tool in pharmacy courses. ${ }^{27}$ In this sense, the VIPAGE software was designed to enable students to interact with real patients in typical pharmacy cases that emphasize that aging is not necessarily a negative experience.

The present study has several strengths. First, unlike our study, the results of other studies assessing the impact of teaching strategies on improving geriatric knowledge and attitudes have been inconsistent. In addition, there is often a dissociation between knowledge and attitudes, with interventions optimizing knowledge without a corresponding improvement in negative attitudes. ${ }^{28}$ Second, studies that use VPs are usually concerned only with the methodological description of tool development, without evaluating the impact of the tools on students' knowledge and attitudes. ${ }^{29}$ In this sense, our study, in addition to 


\section{American Journal of Pharmaceutical Education 2020; 84 (5) Article 7230.}

describing the development of the VIPAGE software, demonstrated the positive impact of this tool on students' knowledge and attitudes. This teaching strategy does not require many resources for its implementation; only a computer laboratory or laptop computers are necessary, together with trained faculty members to teach how to use the software and facilitate a debrief to ensure integration of knowledge.

This study also had limitations. Future studies should be conducted to evaluate the impact of the software on the competencies of students from other academic disciplines. A recognized limitation of this study is that it included students from only two institutions and therefore the results cannot be generalized to pharmacy students in other institutions. Future studies should expand the number of students and pharmacy teaching institutions included to allow greater generalization of the data. As this represents the first study using the VIPAGE software, it was not possible to verify the effect size, owing to the number of available variables. Therefore, future studies on the effectiveness of the software should take the magnitude of the effect into account. The adaptation of some instruments can also be cited as a limitation. Moreover, the difference between the number of male and female students may have limited a more reliable comparison. Future studies should also be conducted to address the issue of how long these competencies (knowledge and attitudes) remain after using the VIPAGE software.

\section{CONCLUSION}

The VIPAGE software positively impacted the geriatric competencies of pharmacy students. Also, the VIPAGE software is one of the first programs to use VPs for teaching geriatrics. By assessing students' knowledge and attitudes toward elderly people before and after using the software the effects of the VIPAGE application were clearly evaluated. The study also allowed us to identify possible modifications that would improve the software. A multidimensional assessment helped us to understand the limitations of VIPAGE and to design changes in the software to improve the abilities of students who performed poorly.

\section{ACKNOWLEDGMENTS}

This study was supported by an academic scholarship from the National Council for Scientific and Technological Development (CNPq) and the Foundation for Research and Technological Innovation Support of the State of Sergipe (FAPITEC/SE). The funders had no role in the study design, data collection and analysis, or decision-making in the publication or preparation of the manuscript. We thank Professor Marigilson Pontes de Siqueira Moura for review of the manuscript.

\section{REFERENCES}

1. Tan ZS, Mulhausen PL, Smith SR, Ruiz JG. Virtual patients in geriatric education. Gerontol Geriatr Educ. 2010;31:163-173. doi: 10.1080/02701961003795813.

2. Smith MA, Benedict N. Effectiveness of educational technology to improve patient care in pharmacy curricula. Am J Pharm Educ. 2015;79:15. doi: 10.5688/ajpe79115.

3. Smith MA, Waite LH. Utilization of a virtual patient for advanced assessment of student performance in pain management. Curr Pharm Teach Learn. 2017;9:893-897. doi: 10.1016/j.cpt1.2017.05.019.

4. Taglieri CA, Crosby SJ, Zimmerman K, Schneider T, Patel DK. Evaluation of the use of a virtual patient on student competence and confidence in performing simulated clinic visits. Am J Pharm Educ. 2017;81:87. doi: 10.5688/ajpe81587.

5. Douglass MA, Casale JP, Skirvin JA, DiVall MV. A virtual patient software program to improve pharmacy student learning in a comprehensive disease management course. Am J Pharm Educ. 2013;77:172. doi: 10.5688/ajpe778172.

6. Menendez E, Balisa-Rocha B, Jabbur-Lopes M, et al. Using a virtual patient system for the teaching of pharmaceutical care. Int $J$ Med Inform. 2015;84:640. doi: 10.1016/j.ijmedinf.2015.05.015.

7. Accreditation Council for Pharmacy Education. Accreditation Standards and Key Elements for the Professional Program in Pharmacy Leading to the Doctor of Pharmacy Degree (Standards 2016). Published February 2015. http://www.acpe-accredit.org/pdf/ Standards2016FINAL.pdf. Accessed May 14, 2020.

8. Adkins DM, Mayhew SL, Gavaza P, Rahman S. Pharmacy students' attitudes toward geriatric nursing home patients. $\mathrm{Am} \mathrm{J}$ Pharm Educ. 2012;76:81. doi: 10.5688/ajpe76581.

9. Bagri AS, Roos BA, Ruiz JG. Simulation technology in geriatric education. Geriatr Aging. 2008;11:596-600.

10. Orton E, Mulhausen P. E-Learning Virtual Patients for Geriatric Education. Gerontol Geriatr Educ. 2008;28:73-88. doi: 10.1300/ J021v28n03_06.

11. Reuben DB, Lee M, Davis JW, et al. Development and validation of a geriatrics attitudes scale for primary care residents. $J$ Am Geriatr Soc. 1998;46:1425-1430. doi: 10.1111/j.1532-5415.1998.tb06012.x 12. Liu Y, Norman IJ, While AE. Nurses' attitudes towards older people: a systematic review. Int J Nurs Stud. 2013;50:1271-1282. doi: 10.1016/j.ijnurstu.2012.11.021.

13. Palmore E. Facts on aging - a short quiz. Gerontol. 1977;17: 315-320. doi: 10.1093/geront/17.4.315.

14. Hussein G, Kawahara N. Adaptive and longitudinal pharmaceutical care instruction using an interactive voice response/ text-to-speech system. Am J Pharm Educ. 2006;70(2):1-8. doi: 10.5688/aj700237.

15. Zary N, Johnson G, Boberg J, Fors UG. Development, implementation and pilot evaluation of a web-based virtual patient case simulation environment - Web-SP. BMC Med Educ.

2006;6(10):1-17. doi: 10.1186/1472-6920-6-10.

16. Kishimoto M, Nagoshi M, Williams S, Masaki KH, Blanchette PL. Knowledge and attitudes about geriatrics of medical students, internal medicine residents, and geriatric medicine fellows. $J \mathrm{Am}$ Geriatr Soc. 2005;53:99-102. doi: 10.1111/j.1532-5415.2005.53018.x. 17. Estus EL. Using Facebook within a geriatric pharmacotherapy course. Am J Pharm Educ. 2010;74:145. doi: 10.5688/aj7408145. 


\section{American Journal of Pharmaceutical Education 2020; 84 (5) Article 7230.}

18. Samra R, Griffiths A, Cox T, Conroy S, Knight A. Changes in medical student and doctor attitudes toward older adults after an intervention: a systematic review. J Am Geriatr Soc. 2013;61:

1188-1196. doi: 10.1111/jgs.12312.

19. Lee M, Reuben DB, Ferrell BA. Multidimensional attitudes of medical residents and geriatrics. J Am Geriatr Soc. 2005;53:489-494. doi: $10.1111 /$ j.1532-5415.2005.53170.x.

20. Gavaza P, Hodges E, Adkins D. Investigating pharmacy students' attitudes toward nursing facility patients after a geriatric rotation. Consul Pharm. 2013;28:502-508. doi: 10.4140/TCP.n. 2013.502.

21. Winn J, Heeter C. Gaming, gender, and time: who makes time to play? Sex Roles. 2009;61:1-13. doi: 10.1007/s11199009-9595-7.

22. Sahin S, Mandiracioglu A, Tekin N, Senuzun F, Akcicek F. Attitudes toward the elderly among the health care providers: reliability and validity of Turkish version of the UCLA geriatrics attitudes (UCLA-GA) scale. Arch Gerontol Geriatr. 2012;55:205-209. doi: 10.1016/j.archger.2011.08.015.

23. Usta YY, Demir Y, Yönder M, Yildiz A. Nursing students' attitudes toward ageism in Turkey. Arch Gerontol Geriatr. 2011;54:90-93. doi: 10.1016/j.archger.2011.02.002.
24. Hweidi IM, Al-Hassan MA. Jordanian nurses' attitudes toward older patients in acute care settings. Int Nurs Rev. 2005;52:225-232. doi: $10.1111 / \mathrm{j} .1466-7657.2005 .00434 . x$.

25. Hughes NJ, Soiza RL, Chua M, et al. Medical student attitudes toward older people and willingness to consider a career in geriatric medicine. J Am Geriatr Soc. 2008;56:334-338. doi: 10.1111/j.15325415.2007.01552.x.

26. Duque G, Gold S, Bergman H. Early clinical exposure to geriatric medicine in second-year medical school students--the McGill experience. J Am Geriatr Soc. 2003;51:544-548. doi: 10.1046/j.1532-5415.2003.51166.x.

27. Jimenez S. Geriatric Content in US doctor of pharmacy degree curricula. Published August 2012. http://fisherpub.sjfc.edu/cgi/ viewcontent.cgi? article $=1000 \&$ context $=$ education_etd. Accessed May 14, 2020.

28. Koh LC. Student attitudes and educational support in caring for older people--a review of literature. Nurse Educ Pract.

2012;12:16-20. doi: 10.1016/j.nepr.2011.04.007.

29. Cook DA, Erwin PJ, Triola MM. Computerized virtual patients in health professions education: a systematic review and metaanalysis. Acad Med. 2010;85:1589-1602. doi: 10.1097/ ACM.0b013e3181edfe13. 